\title{
An Evaluation and Examination of Quiz Tool within Open-Source Learning Management Systems
}

\author{
https://doi.org/10.3991/ijet.v15i10.11638 \\ Randa Obeidallah ${ }^{(凶)}$, Aayat Shdaifat \\ The Hashemite University, Zarqa, Jordan \\ randa.ali@hu.edu.jo
}

\begin{abstract}
Most open-source learning management systems are equipped with a quiz tool, which plays an important role in measuring and evaluating the achievements of a student in a particular e-course. Currently, numerous opensource LMSs are available in the market. In this study, some analysis and comparisons were made between the most used open-source LMSs, including Moodle, ATutor, Eliademy, Sakai, Dokeos, ILIAS, OpenOLAT and Opigno. The study is mainly based on the functionality of the quiz tool that is available within the selected LMSs. This paper study and evaluate the availability of certain features that are divided into sub-categories: questions, result/feedback and quiz setting features.
\end{abstract}

Keywords - Open-source; E-learning; Distance learning; Learning management systems; Assessment tool; Quiz tool

\section{Introduction}

E-Learning is essential in every educational/training institution. The virtual learning environment has emerged to overcome the distance and time barriers in learning. A virtual learning environment is built by using a learning management system (LMS). LMS is a web-based application used for facilitating distance learning and for managing and categorising course materials for both instructors and learners (Alshammari et al., 2016; Blake and Morse, 2016).

LMS support the learning process by establishing a virtual relation activity between instructors and students over the Internet (Zadeh et al., 2017; Anggrainingsih et al., 2016; Yulianandra et al., 2017). According to Wichadee (2015), three main tools must be available in an LMS, namely: a study skill tool, which is used to create course materials (e.g. presentation materials, quizzes and assignments), a communication tool (e.g. announcement boards, forums and chat functions) and a productivity tool.

In this paper, we are concerned with the assessment tool in open-source LMSs. As part of e-learning, online exams, also known as online assessments or computer-based exams, are used to evaluate the achievements of students in an online course. Assessment tools support the educational process by facilitating record keeping, 
promoting trouble-free sessions, reducing stress during exams and lessening costs (Sindre and Vegendla, 2015).

E-assessments are designed to measure the quality, validity and reliability of an ecourse, provide feedback to students, measure their experiences and evaluate the efficiency of the delivered course (Lees and Carpenter, 2012; Filippi and Spalanzani, 2012). As one of the most important phases in education (Richard, 2015), assessment is performed to determine what students have learned and whether the intended course outcomes have been achieved or not (Gikandi et al., 2011). Most of LMSs support the use of assessment tools. Quizzes and tests are important parts of open-source LMSs (Wichadee, 2015). These tools reduce the efforts of teachers in their preparation of tests and minimise the chances for an inaccurate evaluation (Alajbeg et al., 2017).

Over the past few years, many LMSs are being offered by different vendors. These LMSs can be grouped into three main categories: proprietary LMSs, open-source LMSs and cloud-based LMSs.

Today; many organisations are moving toward utilizing open-source LMSs. This is because of the excellent features that open-source LMSs provide such as: no additional fees, no need for licence or support requirements. Open-source LMSs also provide powerful online support communities that offer flexibility, no cost and security (Hussain et al., 2011). Benefits of adopting open-source software is to decrease cost, fix bugs and errors quickly with high quality alternative solutions (Namisiko et. al., 2014).

In this paper, several open-source LMSs were investigated, including Moodle, ATutor, Eliademy, Sakai, Dokeos, ILIAS, OpenOLAT and Opigno based on their assessment tools. These LMSs were selected based upon most demanded from dozens of available open-source LMSs in the market.

This paper is structured as follows. Section 2 presents a literature review of opensource LMSs. Section 3 introduce the method of this study and list summery of the selected open-source LMSs. Section 4 presents the criteria for assessment tools features of the selected open-source LMSs. Results and discussion are introduced in section 5 , and finally conclusion is introduced in section 6 .

\section{Open-Source LMSs}

LMS is a software used to help students and instructors in e-Learning (Hussain et al., 2011). The purpose of LMSs is to deliver knowledge contents online, open-source LMS must be available, usable, scalable, interoperable, stable and secure (Machado and Tao, 2007; Al-Busaidi and Al-Shihi, 2012).

Adopting an open-source software can reduce the cost of high-quality products and quickly fix bugs and errors by relying on online communities (Namisiko et al., 2014). Moreover, an open-source code can be modified to suit any institution without affecting its security or quality (Hussain et al., 2011).

In order to select the appropriate open-source software, Wheeler (2011) suggested the use of four steps: identify candidates, read existing reviews, compare the leading programs' basic attributes to your needs, and analyze the top candidates in more 
depth. In addition, open-source LMS must support six functions: creation, organisation, delivery, communication, collaboration and assessment (Khalkhali, 2014). Moreover; an open-source LMS must have course management functions, support SCORM, able to use creation tools such as Microsoft Word, Microsoft PowerPoint and Adobe Flash, support multiple languages and be able to work with other LMSs (Aydin and Tirkes, 2010).

Usually, users choose LMS software mainly because of its functionality and ease of use. A user-friendly software is important to increase number of users and easily make good interaction between users (Yulianandra et al., 2017).

Many researchers have compared different open-source LMSs based on certain factors and items. For instance, Anggrainingsih et al. (2016) compared Moodle, ATutor and ILIAS based on their flexibility and maintainability. Desai et al. (2015) compared Moodle, Canvas, Gibbon, OLAT, Blackboard, Bright Space and Sakai CLE based on their usability, services, functions, technical requirements and standards. Cavus and Zabadi (2014) compared ATutor, Claroline, Dokeos, Ilias, Moodle and Sakai based on their communication functions and the user-friendliness of their interfaces. Hussain et al. (2011) compared OLAT, ATutor, Moodle, eFront, Bodington and Sakai based on their learning models, modules, hardware and software requirements.

\section{$3 \quad$ Study Method}

Dozens of open-source LMSs are available in the market. The selected software had been evaluated by comparative and contrastive observational approach and Business Readiness Rating (BRR). Information were conducted from many opensource LMSs websites (Table 1), demo programs and examine reviews of the quiz tool feature given at internet. The chosen open-source LMSs were investigated in detail according to features of quiz tool. Eight LMSs had been selected and their quiz tools had been evaluated and compared reflecting the availability of quiz tool features (questions, result/feedback and quiz setting). The most demanded Open-source LMS are selected to be evaluated: Moodle, ATutor, Eliademy, Sakai, Dokeos, ILIAS, OpenOLAT and Opigno.

Table 1 lists URL of selected open-source LMS, each of which is briefly described as follows:

\subsection{Moodle}

Moodle stands for modular object-oriented dynamic learning environment. This LMS was developed by Martin Dougiamas in 2002 as a course management or management learning system. Moodle was written in PHP, distributed under the GNU general public licence and supports over 100 languages. The basic idea of Moodle lies in its 'social constructivist pedagogy' (Yaowen, 2013), that is, maintaining a positive interaction between the teacher and the student. Moodle offers numerous functions 
that support the educational process, including chats, forums, quizzes, lessons, assignments and glossaries (Patel and Patel, 2017; Moodle, 2018).

ATutor: ATutor is an open-source web-based learning content management system released in late 2002 for developing online courses and creating e-Learning content. This application was written in PHP and distributed under the GNU general public licence. ATutor offers excellent features for both instructors and students, including functions for creating online courses, developing, reusing, and sharing e-Learning content and ability to integrate with social networks (Mihaelaion, 2012; ATutor, 2018).

\subsection{Eliademy}

Eliademy is an e-Learning platform that allows teachers and students to create, share and manage online courses. This application is based on the virtual learning environment of Moodle (Eliademy, 2018; Tanaś, 2015). Eliademy was developed by CBTec Oy, launched all over the world in 2013 and supports 32 languages. Courses in Eliademy use documents, pictures and videos, support quizzes and assignments and allow teachers to give feedback to students (Perwonegoro and Syafei, 2016).

\subsection{Sakai}

Sakai is an open-source software that provides a flexible environment for improved teaching, learning, research and collaboration. Sakai was developed by the University of Michigan, Indiana University, Massachusetts Institute of Technology and Stanford University from previously available tools. This Java-based software became freely available on March 2005 and has been translated into more than 20 languages. Sakai offers the standard LMS features as well as some additional options for creating courses, launching collaborative projects and conducting research (Sakai, 2018).

\subsection{Dokeos}

Dokeos is an open-source e-Learning software that manages learning and collaboration activities. This application was developed in 1999 at the University of Louvain in response to a triple need for training, motivation and evaluation. Dokeos has been translated into 31 languages and is available in different versions, although only the Dokeos community edition can be downloaded for free (Dokeos, 2018).

\subsection{ILIAS}

ILIAS is a web-based LMS that provides a flexible online working and learning environment with integrated tools. Knowledge materials may also be available for non-registered users. ILIAS was developed at the University of Cologne in 1998, written in PHP, published under the GNU general public licence and translated into 
28 languages. This application is considered one of the first LMSs that have been used in universities (ILIAS, 2018).

\subsection{OpenOLAT}

OpenOLAT is an open-source web-based LMS for teaching, education, assessment and communication. OLAT stands for 'online learning and training'. This application was initiated as a branch of 7.1 OLAT and developed using Java at the University of Zurich in 2011. OpenOLAT provides many features for both students and teachers (OpenOLAT, 2018).

Opigno: Opigno is an open-source e-Learning platform based on Drupal. This application is distinguished because of its high compatibility with SCORM and TinCan as well as its adaptable integration with other Drupal systems. Opigno offers student management features and many easy-to-use tools needed in learning.

Table 1. URLs of Selected Open-Source LMSs

\begin{tabular}{|l|l|}
\hline \multicolumn{1}{|c|}{ Open-source LMS } & \multicolumn{1}{c|}{ URL } \\
\hline Moodle & https://www.moodle.org/ \\
\hline ATutor & http://www.atutor.ca/ \\
\hline Eliademy & https://eliademy.com/ \\
\hline Sakai & https://www.sakaiproject.org/ \\
\hline Dokeos & https://www.dokeos.com/ \\
\hline ILIAS & https://www.ilias.de \\
\hline OpenOLAT & https://www.openolat.com \\
\hline Opigno & https://www.opigno.org \\
\hline
\end{tabular}

\section{$4 \quad$ Quiz Tool Features}

An excellent assessment tool and quiz tool in open-source LMSs must include features for both the teacher and the student. For teachers, an assessment tool must be able to create quizzes and homework quickly, add questions easily, provide feedback and support, and randomise questions. Meanwhile, for students, an assessment tool must allow them to review a question, retake a quiz if needed and obtain results and feedback directly after answering a question correctly or incorrectly (Kruger et al., 2015). Another important feature of an assessment tool is the availability of a question bank, which is a secured pool of questions that helps users save time (Abu Mansour, 2017).

In this paper, we examined features of the quiz tool within the selected open-source LMSs. The following are a summarized list of important features; each is divided into sub-categories including:

\subsection{Questions feature}

This feature includes some important categories, such as: 
1. Question type: This feature involves the types of questions that can be created using an assessment tool (e.g. multiple choice questions, fill in the blanks, numerical matching and ordering).

2. Randomised questions: This feature allows instructors to present their questions to students in a random order.

3. Question bank: This feature allows instructors to create, preview and update their questions in a database and then insert all or only part of these questions into their quizzes.

4. Category: This feature helps instructors efficiently use the question bank by dividing their questions into different categories based on specific topics.

5. Import and export file: This feature allows instructors to import their questions from different sources and then save and export these questions to other file types.

\subsection{Result and Feedback Feature}

This feature includes the following categories:

1. Grade report

- For instructors, this feature allows them to generate a statistical report of the test results

- For students, this feature offers them their test grades and total grades to find out if they have passed or failed their exams

2. Feedback

- For instructors, this feature helps them find out the strengths and weaknesses of their students in certain topics based on their test results. They can also generate a statistical report for each student

- For students, this feature gives them feedback on all the questions they have answered incorrectly in a test

- Course outcome: This feature helps link each question to the course outcomes as mentioned in the course curriculum

\subsection{Quiz setting feature}

Assessment tools is supposed to offer a quiz setting feature for both instructors and students to control the following:

1. Layout: This feature allows users to customize the appearance of questions in a test, either showing only one question per page or multiple questions in a page.

2. Quiz attempts: This feature shows how many times a student can attempt taking a quiz.

3. Time limit: This feature presents the time left for a student to complete a test as well as records the time s/he began and completed the test. 
4. Authentication: This feature ensures the security of a test and instructs students on how they can take the test.

\section{$5 \quad$ Results and Discussion}

Results were extracted by examining open-source LMS demo programs and analysing the quiz tool features from websites of Moodle, ATutor, Eliademy, Sakai, Dokeos, ILIAS, OpenOLAT and Opigno.

The results of the comparison based upon Questions feature are summarized in Table 2. The results showed that the selected open-source LMSs offer many types of questions, including multiple choice, fill in the blanks, numerical matching, ordering, hot spots and essays. Moodle and Dokeos provide more types of questions compared with the other LMSs. Dokeos provides several options for assessment, including eLearning, paper formats and face-to-face evaluation sessions.

Moodle and Opigno have the ability to integrate with H5P to provide more interactive types. The ability to randomize questions in test for every student is available in all open-source LMSs. Question bank and Category are also available in all assessment tool except Eliademy. Question bank is known as question pool in Sakai and ILIAS and scenario in Dokeos.

Questions can be imported and/or exported in all open-source LMSs except for Eliademy. QTI XML is the main file format used in these LMSs. Moodle supports more file formats in importing and exporting files, Opigno supports more file formats in exporting and both Dokeos and Opigno support the importing of Excel files only for multiple choice questions.

Regarding Result and feedback feature, the results showed (Table 3) that all opensource LMSs provide grade reports to both the instructor and student albeit with some differences. Moodle and ATutor immediately provide statistical reports to instructors. Sakai immediately presents the results only if the type of question is not short answer/essay, file upload and audio recording. Dokeos requires manual grading for paper format questions and/or face-to-face evaluation sessions. Opigno displays the results to users during or after a quiz.

Providing feedback to students is optional in these LMSs. Students can receive feedback either immediately after answering each question or after completing a test. Opigno provides automatic and manual feedback features, whilst unlike the other LMSs, Moodle can link each question to the course outcomes.

Table 4 shows the results of LMSs based on their quiz setting feature. All these LMSs have built-in editors that allow users to customise their quiz layouts as well as specify a timeframe for a test to be completed. Each user can decide when to start and end a test. Students may attempt taking the quiz only once or for an unlimited number of times. However, OpenOLAT only allows students to attempt completing a quiz for a maximum of 20 times.

All these LMSs ask for a course login password from the users. For security reasons, Moodle and ILIAS ask users for a second password to access a test. Dokeos and ILIAS can send exclusive invites to certain students to take a test, whilst Moodle 
and OpenOLAT have the feature of allowing only those users with specific IP addresses to take a test.

Table 2. Comparison results based on the questions criterion

\begin{tabular}{|c|c|c|c|c|c|c|c|c|c|}
\hline & $\begin{array}{l}\text { MS } \\
\text { ature }\end{array}$ & Moodle & ATutor & Eliademy & Sakai & Dokeos & ILIAS & $\begin{array}{c}\text { OpenOL } \\
\text { AT }\end{array}$ & Opigno \\
\hline Quest & n type & $\begin{array}{l}16 \text { types of } \\
\text { standard } \\
\text { questions } \\
\text { and } 50 \\
\text { types of } \\
\text { third-party } \\
\text { questions }\end{array}$ & 8 & 3 & 9 & 29 & 9 & 5 & 8 \\
\hline $\begin{array}{l}\text { Rand } \\
\text { quest }\end{array}$ & $\begin{array}{l}\text { nised } \\
\mathrm{ns}\end{array}$ & V & V & $\sqrt{ }$ & V & V & V & V & V \\
\hline Quest & n bank & V & V & x & V & V & V & V & $\sqrt{ }$ \\
\hline Categ & & $\sqrt{ }$ & $\sqrt{ }$ & $x$ & $\sqrt{ }$ & $\sqrt{ }$ & $\sqrt{ }$ & $\sqrt{ }$ & $\sqrt{ }$ \\
\hline & $\begin{array}{l}\text { Import } \\
\text { file }\end{array}$ & $\begin{array}{l}\text { Aiken } \\
\text { QTI XML } \\
\text { Blackboard } \\
\text { files }\end{array}$ & \begin{tabular}{|l|} 
QTI \\
XML
\end{tabular} & x & \begin{tabular}{|l|} 
QTI \\
XML
\end{tabular} & $\begin{array}{l}\text { XLS for } \\
\text { multiple } \\
\text { choice } \\
\text { questions } \\
\text { only }\end{array}$ & QTI XML & QTI XML & $\begin{array}{l}\text { XLS } \\
\text { multiple } \\
\text { choice } \\
\text { questions } \\
\text { only }\end{array}$ \\
\hline Files & $\begin{array}{l}\text { Export } \\
\text { file }\end{array}$ & \begin{tabular}{|l|} 
GIFT \\
format \\
Moodle \\
XML \\
format \\
XHTML \\
format
\end{tabular} & \begin{tabular}{|l} 
QTI \\
XML
\end{tabular} & $x$ & \begin{tabular}{|l} 
QTI \\
XML
\end{tabular} & QTI XML & QTI XML & QTI XML & \begin{tabular}{|l|} 
CSV \\
XLS \\
DOC \\
BasicTXT \\
XML
\end{tabular} \\
\hline
\end{tabular}

Table 3. Comparison results based on the result and feedback criterion

\begin{tabular}{|l|l|c|c|c|c|c|c|c|c|}
\hline \multicolumn{2}{|c|}{$\begin{array}{c}\text { LMS } \\
\text { Feature }\end{array}$} & Moodle & ATutor & Eliademy & Sakai & Dokeos & ILIAS & $\begin{array}{c}\text { OpenOLA } \\
\text { T }\end{array}$ & Opigno \\
\hline \multirow{2}{*}{$\begin{array}{l}\text { Grade } \\
\text { report }\end{array}$} & Instructor & $\sqrt{ }$ & $\sqrt{ }$ & $\sqrt{ }$ & $\sqrt{ }$ & $\sqrt{ }$ & $\sqrt{ }$ & $\sqrt{ }$ & $\sqrt{ }$ \\
\cline { 2 - 10 } Student & $\sqrt{ }$ & $\sqrt{ }$ & $\sqrt{ }$ & $\sqrt{ }$ & $\sqrt{ }$ & $\sqrt{ }$ & $\sqrt{ }$ & $\sqrt{ }$ \\
\hline \multirow{2}{*}{ Feedback } & Instructor & $\sqrt{ }$ & $\sqrt{ }$ & $\sqrt{ }$ & $\sqrt{ }$ & $\sqrt{ }$ & $\sqrt{ }$ & $\sqrt{ }$ & $\sqrt{ }$ \\
\cline { 2 - 10 } & Student & $\sqrt{ }$ & $\sqrt{ }$ & $\sqrt{ }$ & $\sqrt{ }$ & $\sqrt{ }$ & $\sqrt{ }$ & $\sqrt{ }$ & $\sqrt{ }$ \\
\hline \multicolumn{2}{l}{ Course outcome } & $\sqrt{ }$ & $x$ & $\chi$ & $\chi$ & $x$ & $x$ & $x$ & $x$ \\
\hline
\end{tabular}


Table 4. Comparison results based on the quiz setting criterion

\begin{tabular}{|c|c|c|c|c|c|c|c|c|}
\hline $\begin{array}{c}\text { LMS } \\
\text { Feature }\end{array}$ & Moodle & ATutor & $\begin{array}{c}\text { Eliade } \\
\text { my }\end{array}$ & Sakai & Dokeos & ILIAS & OpenOLAT & Opigno \\
\hline Layout & $\sqrt{ }$ & $\sqrt{ }$ & $\sqrt{ }$ & $\sqrt{ }$ & $\sqrt{ }$ & $\sqrt{ }$ & $\sqrt{ }$ & $\sqrt{ }$ \\
\hline Quiz attempt & $\sqrt{ }$ & $\sqrt{ }$ & $\sqrt{ }$ & $\sqrt{ }$ & $\sqrt{ }$ & $\sqrt{ }$ & $\sqrt{ }$ & $\sqrt{ }$ \\
\hline Time limit & $\sqrt{ }$ & $\sqrt{ }$ & $\sqrt{ }$ & $\sqrt{ }$ & $\sqrt{ }$ & $\sqrt{ }$ & $\sqrt{ }$ & $\sqrt{ }$ \\
\hline Authentication & $\begin{array}{l}\text { Course login } \\
\text { password } \\
\text { Password to } \\
\text { allow users to } \\
\text { start a quiz } \\
\text { Specific IP } \\
\text { addresses to } \\
\text { access a quiz }\end{array}$ & $\begin{array}{l}\text { Course } \\
\text { login } \\
\text { passwor } \\
\text { d }\end{array}$ & $\begin{array}{l}\text { Course } \\
\text { login } \\
\text { passwor } \\
\text { d }\end{array}$ & $\begin{array}{l}\text { Course } \\
\text { login } \\
\text { passwor } \\
\text { d }\end{array}$ & $\begin{array}{l}\text { Course } \\
\text { login } \\
\text { password } \\
\text { Exclusive } \\
\text { invites to } \\
\text { certain } \\
\text { users }\end{array}$ & $\begin{array}{l}\text { Course login } \\
\text { password } \\
\text { Password to } \\
\text { allow users to } \\
\text { start a quiz } \\
\text { Exclusive } \\
\text { invites to } \\
\text { certain users }\end{array}$ & $\begin{array}{l}\text { Course login } \\
\text { password } \\
\text { Specific IP } \\
\text { addresses to } \\
\text { access a quiz }\end{array}$ & $\begin{array}{l}\text { Course } \\
\text { login } \\
\text { password }\end{array}$ \\
\hline
\end{tabular}

\section{Conclusion}

Many institutions are currently using open-source LMSs to improve their educational and training processes. As part of these processes, assessments are performed to evaluate both the student and the course. Open-source LMSs offer an assessment tool, also known as a quiz tool, to design and manage tests.

The selection of the most appropriate open-source LMS greatly depends on the requirements of an institution. Each open-source LMS provides several important features.

This paper investigates several open-source LMSs, including Moodle, ATutor, Eliademy, Sakai, Dokeos, ILIAS, OpenOLAT and Opigno, based on their quiz tools. Three features are analysed and examined in the study, namely, questions, result and feedback and quiz setting features. We can briefly say that Moodle emerges as the best open-source LMS based on its quiz tool. And Eliademy LMS is the least since it does not include a question bank, category neither import/export file.

The results showed that Moodle and Dokeos provide a large number of question types. All these LMSs provide grade reports and quiz feedback to their users. Moodle is the only open-source LMSs that can link each question to the course outcomes. Both Moodle and ILIAS ask users to provide a second password before accessing a test.

\section{$7 \quad$ References}

[1] Alajbeg, T., Sokele, M., \& Šimović, V. (2017, May). Determination of time criteria for assessment in Learning Management Systems. In Information and Communication Technology, Electronics and Microelectronics (MIPRO), 2017 40th International Convention on (pp. 910-914). IEEE. https://doi.org/10.23919/mipro.2017.7973552

[2] AbuMansour, H. Y. (2017, October). Proposed Bio-authentication System for Question Bank in Learning Management Systems. In Computer Systems and Applications 
(AICCSA), 2017 IEEE/ACS 14th International Conference on (pp. 489-494). IEEE. https://doi.org/10.1109/aiccsa.2017.215

[3] Al-Busaidi, K. A., \& Al-Shihi, H. (2012). Key factors to instructors' satisfaction of learning management systems in blended learning. Journal of Computing in Higher Education, 24(1), 18-39. https://doi.org/10.1007/s12528-011-9051-x

[4] Alina-Mihaela ION, 'Compared Analysis of Representative Learning and Content Management Systems used in Education', Informatica Economică vol. 16, no. 1/2012.

[5] Alshammari, S. H., Ali, M. B., \& Rosli, M. S. (2016). The Influences of Technical Support, Self-Efficacy and Instructional Design on the Usage and Acceptance of LMS: A Comprehensive Review. Turkish Online Journal of Educational TechnologyTOJET, 15(2), 116-125.

[6] Anggrainingsih, R., Johannanda, B. O. P., Kuswara, A. P., Wahyuningsih, D., \& Rejekiningsih, T. (2016, August). Comparison of maintainability and flexibility on open source LMS. InTechnology of Information and Communication (ISemantic), International Seminar on Application for (pp. 273-277). IEEE. https://doi.org/10.1109/ isemantic.2016.7873850

[7] Aydin, C. C., \& Tirkes, G. (2010, April). Open source learning management systems in elearning and Moodle. InEducation Engineering (EDUCON), 2010 IEEE (pp. 593-600). IEEE. https://doi.org/10.1109/educon.2010.5492522

[8] Baleghi-Zadeh, S., Ayub, A. F. M., Mahmud, R., \& Daud, S. M. (2017). The influence of system interactivity and technical support on learning management system utilization. Knowledge Management \& E-Learning, 9(1), 50. https://doi.org/10.34105/j. kmel.2017.09.004

[9] Blake, M. R., \& Morse, C. (2016). Keeping your options open: A review of open source and free technologies for instructional use in higher education. Reference Services Review, 44(3), 375-389. https://doi.org/10.1108/rsr-05-2016-0033

[10] Cavus, N., \& Zabadi, T. (2014). A comparison of open source learning management systems. Procedia-Social and Behavioral Sciences, 143, 521-526. https://doi.org/10.10 16/j.sbspro.2014.07.430

[11] Desai, R., Ajay, V. K., \& Kumar, K. (2015, December). OSLMS: Open source software to E Learning-a comparative study. In Control, Instrumentation, Communication and Computational Technologies (ICCICCT), 2015 International Conference on (pp. 33-37). IEEE. https://doi.org/10.1109/iccicct.2015.7475244

[12] El Khalkhali, I. (2014, January). The student experience of an open source Learning Management System. InComputer Applications and Information Systems (WCCAIS), 2014 World Congress on (pp. 1-6). IEEE. https://doi.org/10.1109/wccais.2014.6916654

[13] Filippi, L. and Spalanzani, A. (2012) 'Using technology in an e-learning training course: the role of the student's personal environment', International Journal of Business Information Systems, Vol. 11, No. 1, pp.41-68. https://doi.org/10.1504/ijbis.2012.048341

[14] Gikandi, J. W., Morrow, D., \& Davis, N. E. (2011). Online formative assessment in higher education: A review of the literature. Computers \& education, 57(4), 2333-2351. https://doi.org/10.1016/j.compedu.2011.06.004

[15] Sindre, G., \& Vegendla, A. (2015). E-exams and exam process improvement. InNIK.

[16] Hussain, S., Wang, Z., \& Sun, C. A. (2011, October). A comparative study of open-source learning management systems. InOpen-Source Software for Scientific Computation (OSSC), 2011 International Workshop on (pp. 86-93). IEEE. https://doi.org/10.1109/ ossc. 2011.6184700 
[17] Kruger, D., Inman, S., Ding, Z., Kang, Y., Kuna, P., Liu, Y., \& Wang, Y. (2015). Improving teacher effectiveness: Designing better assessment tools in learning management systems. Future Internet, 7(4), 484-499. https://doi.org/10.3390/fi7040484

[18] Lees, D. and Carpenter, V. (2012) 'A qualitative assessment of providing quality electronically mediated feedback for students in higher education', International Journal Learning Technology, Vol. 7, No. 1, pp.95-110. https://doi.org/10.1504/ijlt.2012.046868

[19] Namisiko, P., Mindila, R., Chepkoech, E., \& Nyeris, R. (2014). A review of application of web 2.0 and open source softwares in E-learning: A baseline survey in a private university, Kenya. International Journal of Computer Science Issues (IJCSI), 11(2), 190.

[20] Machado, M., \& Tao, E. (2007, October). Blackboard vs. Moodle: Comparing user experience of learning management systems. In Frontiers in education conference-global engineering: knowledge without borders, opportunities without passports, 2007. FIE'07. 37th annual (pp. S4J-7). IEEE. https://doi.org/10.1109/fie.2007.4417910

[21] Patel D. and P. Patel, "Blended Learning in Higher Education using MOODLE Open Source Learning Management Tool" , nternational Journal of Advanced Research in Computer Science, Volume 8, No. 5, May - June 2017.

[22] Perwonegoro Y. and Syafei F.," REPARING ELIADEMY FOR E-LEARNING MEDIA IN ENGLISH LANGUAGE TEACHING “, Journal of English Language Teaching Volume 5 No. 1 Serie D,2016.

[23] Richard, N. (2015). The Form of Examination to be used for effective assessment In Institutions of Higher Learning: Views of lecturers from Four Universities in Zimbabwe. Am. J. Soc. Mgmt. Sci, 6(1), 18-23.

[24] Wheeler D.A.,How to evaluate open source software / free software (oss/fs) programs, http://www.dwheeler.com/oss fs eval.html, Accessed 16th October 2018.

[25] Wichadee, S. (2015). Factors related to faculty members' attitude and adoption of a learning management system. TOJET: The Turkish Online Journal of Educational Technology, 14(4).

[26] Yaowen X., "Computer Network Course Evaluation based on Moodle Platform", Applied Mechanics and Materials Vols. 380-384 (2013) pp 2340-2343. https://doi.org/10.4028/ www.scientific.net/amm.380-384.2340

[27] Yulianandra P., Wibirama S. \& SantosaP (2017), Examining the Effect of Website Complexity and Task Complexity in Web-Based Learning Management System, 1st International Conference on Informatics and Computational Sciences (ICICoS) , 2017. https://doi.org/10.1109/icicos.2017.8276348

\section{Authors}

Randa Obeidallah works as a Tutor in Computer Information System Department in The Hashemite University. She obtained her Masters in Computer Information System from Jordan University in 2009. Her Research interests are involved in Information Retrieval, e-learning Systems, and Information systems.

Aayat Shdaifat works as a Tutor in Basic Science, Department in The Hashemite University. She obtained her Masters in Computer Information System from Jordan University in 2009. Her research interests are involved in Services Composition, learning and information system. Email: aayat@hu.edu.jo.

Article submitted 2019-09-07. Resubmitted 2019-10-18. Final acceptance 2019-10-18. Final version published as submitted by the authors. 